\title{
Associations between quality of relationships and life satisfaction of older mothers in Estonia, Germany, Russia and China
}

\author{
JING WU*, KAIRI KASEARU†, AIRI VÄRNIK*††, \\ LIINA-MAI TOODING + and GISELA TROMMSDORFF
}

\begin{abstract}
The aim of the current study is to examine the associations between the quality of relationships and life satisfaction of older mothers in Estonia, Germany, Russia and the People's Republic of China, based on the assumptions of the Family Change Theory. The role of satisfaction with family life as the probable mediating factor is considered. Estonian older mothers reported the least admiration and intimacy in their relationships with their adult daughters, and the least satisfaction with family life compared to German, Russian and Chinese mothers. German older mothers perceived the most admiration from their adult daughters and were the most satisfied with both their family and general life. Russian older mothers were the least satisfied with their general life compared to their counterparts in Estonia, Germany and China. The results from the Structural Equation Modelling showed that the relationship between satisfaction with family life and general life satisfaction was statistically significant in all countries except Russia. The satisfaction with family life as a mediating factor might strengthen the positive and negative aspects of intergenerational relationships on the life satisfaction of older mothers. The findings indicated that the emotional closeness and intergenerational relationships in families during the process of transition and globalisation play an important role in the life satisfaction of older mothers in these four countries.
\end{abstract}

$\boldsymbol{K E Y} W O R D S$ - quality of relationship, satisfaction with family life, life satisfaction, culture, Family Change Theory, Structural Equation Modelling.

* Estonian-Swedish Mental Health and Suicidology Institute, Tallinn, Estonia.

$\dagger$ Institute of Social Studies, University of Tartu, Estonia.

+ Institute of Social Work, Tallinn University, Estonia.

$\S$ Department of Psychology, University of Konstanz, Germany. 


\section{Introduction}

Despite a large volume of literature on life satisfaction, most studies have focused on the effect of socio-economic factors or the influence of macroeconomic processes on life satisfaction (Dolan, Peasgood and White 20o8). Relatively few studies have investigated the association between life satisfaction and intergenerational relationships in older age. Increased longevity and the inability, reluctance or unwillingness of societies to meet the needs of older people place the family as their main source of care and support (Lowenstein, Katz and Gur-Yaish 2007; Moor and Komter 2008). Even though the importance of providing instrumental support has decreased, the emotional closeness and support between generations has maintained its significance (Künemund 2008). It is claimed that due to individualisation, autonomy and self-expression, the importance of individual dependencies is decreasing and family ties are weakening in Western cultures (Inglehart and Welzel 2005).

The Family Change Theory (Kagitcibasi 2007) is an approach which can be used to explain how the processes of modernisation and globalisation affect the family. This theory takes a global perspective and specifically contrasts non-Western and Western family cultures (Mayer 2013). According to Kagitcibasi (2007), the family model of emotional interdependence is a result of the modernisation process, which is growing out from the model of (total) interdependence. In the emotional interdependence model, personal autonomy is gaining importance, while material interdependence and traditional hierarchies in family relations are losing their significance; however, emotional closeness and relationship orientation continue to be important.

We follow the assumption that intergenerational relations might contribute to individual wellbeing in old age. Previous research has focused more on support exchange, reciprocity and intergenerational relationships (Laidmäe et al. 2011; Lowenstein, Katz and Gur-Yaish 2007; Schwarz et al. $2010 b)$ and less on the relations between the quality of the relationship and life satisfaction. Martin and Westerhof (2003) have shown that contact with family members and the assumed help and care from family members are positively associated with wellbeing. Intergenerational family bonds serve as markers for differences in socialisation, roles, culture, values and access to resources, thereby shaping family relations (Lowenstein 2007; Lowenstein, Katz and Gur-Yaish 2007).

Mother-daughter bonds tend to be the strongest and most enduring of filial connections according to some American empirical studies (Fingerman 1996; Rossi 1993; Rossi and Rossi 1990). It was found that 75 per cent of American older mothers regard their daughters as among 


\section{Jing Wu et al.}

the three most important people in their lives, and as the person they are most likely to talk to when worried and to request help from when in need (Bodner and Cohen-Fridel 2010; Fingerman 1996, 2001). This begs the question of whether older people's life satisfaction depends on their intergenerational family relations (Lowenstein, Katz and Gur-Yaish 2007; Silverstein and Bengtson 1991). This study will investigate the associations between the relationship quality with adult daughters and the wellbeing of older mothers, focusing particularly on their general life satisfaction and satisfaction with family life.

Previous research has mostly been carried out using European-American samples, which calls into question the universality of the above-reported result across diverse cultures. This study aims to: (a) describe the differences of the mother-adult daughter relationships and satisfaction with life and the family in four different societies-Estonia, Germany, Russia and the People's Republic of China; (b) compare the associations between relationships and satisfaction with family life; and (c) examine whether the association between relationship quality and the older mothers' life satisfaction is mediated by the older mothers' satisfaction with family life.

\section{Intergenerational relationships in Estonia}

Historically, Estonia was greatly influenced by Germany and Russia as it was ruled by Russian governors and governed by German gentry, whose customs and traditions have been integrated into the cultural heritage of Estonia. Estonia and Russia share the common historical background of having belonged to the Soviet Union. The Soviet context was characterised by high secularisation, relative economic security and state-subsidised child care, all of which laid the groundwork for the adoption of individualistic values and norms. However, these norms were impeded by the official ideology of collectivism and strong censorship of alternatives (Gerber and Berman 2010).

The collapse of the Soviet Union and the removal of social constraints made it possible to behave according to individualistic values. Adapting to Western institutions after the Soviet era brought about numerous opportunities for Estonians to reformulate their values, ideals, practices and views of themselves, as expressed in the following (Pajumets 2012): rising individualism, self-actualisation, autonomy, self-reliance, etc. (Lauristin 1997). Multigeneration families were widespread in Estonia in the past, especially in the countryside, where grandparents, parents, children and grandchildren lived under the same roof. To a large extent, this form has recently been replaced by nuclear families, where parents and children live together, with the oldest generation frequently living separately from the youngest (Laidmäe 
et al. 2010; Narusk and Hansson 1999). Recent analyses have shown that during the 199os, the networks of giving and receiving help weakened, and especially younger cohorts reduced their giving of support to parents and grandparents (Kasearu and Kutsar 2010). It highlights the possible gap between the expectations of the older generations of receiving help and the possibilities and willingness of the younger generations of giving help.

\section{Intergenerational relationships in Germany}

In a modernised, affluent and individualistic society such as Germany, the more general motive underlying the reciprocity motive might be based on the value of independence, including the value of not being indebted to others (Schwarz et $a l .2010 b$ ). In Germany, late marriage and the related large age gap between generations as well as bilineal descent reduce affective solidarity, on the one hand (Nauck 2009). On the other hand, Germany is also characterised by the norm of respect for parents and an obligation to mutually support family members (Schwarz et al. $2010 b$ ). Frequent contact between the generations is the norm, and the exchange of support is continuous. The family is a major source of social support in Germany; moreover, as a result of the relatively high pensions of Germans, more financial support flows from old parents to their adult children than vice versa (Albertini, Kohli and Vogel 2007; Szydlik 2008). Parent-child relationships are rather structured on the basis of equal partnership, where reciprocal acceptance and exchange are based on individualism and independence (Rothbaum et al. 200o; Trommsdorff and Kornadt 2003; Trommsdorff and Schwarz 2007). In this context, the developmental task is to focus on the autonomy of parents and children alike. This becomes more prevalent during and after adolescence, when adult children start a family of their own (Trommsdorff and Schwarz 2007).

\section{Intergenerational relationships in Russia}

Russia, which had a planned economy and socialist government in the past, is currently experiencing economic deregulation and political transformation; this is certainly a great challenge for kinship relationships with regard to gaining and distributing material resources. Kinship members are an essential resource of mutual services in the production and distribution of material goods (Nauck 20o9).

In Russia, households of several generations are a common living arrangement, and the patrilineal system is the dominant form of kinship organisation (Mitterauer and Kagan 1982; Nauck 2009). Early marriage and relatively small age gaps between generations increase affective solidarity (Nauck 2009). Because of the institutional arrangements, family 
members often have 'no choice', and those kinship relationships do not depend very much on individual preference (Nauck 2009). Hence, Russians are more likely to believe that it is important to provide help for family members in need due to the more limited public welfare system, which is common in Eastern countries as opposed to Western European countries (Dykstra 2010). However, as stated by Kasearu and Kutsar (2013), the shortage of public welfare services may decrease the affective solidarity. Adult children feel responsible for the wellbeing of their older parents; nevertheless, the obligation and lack of resources (money, time, skills, etc.) become a burden and may challenge the quality of relationships between adult children and older parents, which in turn might have a negative influence on the wellbeing of both sides.

\section{Intergenerational relationships in China}

Even though the communist ideology still exists both in present-day China and among former Soviet countries, China has a different pattern of intergenerational relationships owing to Confucianism and its influence on the family. For centuries, Chinese people have endorsed and exercised filial piety as the paramount principle governing interpersonal relations within and outside families. As a result, Chinese people are accustomed to hierarchical relations more than Westerners (Bond 1991; Hofstede 1991; Yue and $\mathrm{Ng}$ 1999). In China, filial responsibility for senior care is taken for granted and the majority of older parents are supported by their adult children (Chen and Silverstein 2000). The family, most notably adult children, serves as the primary source of old-age support for Chinese older people, especially in rural China where more than two-thirds of the older people depend on their children for financial support (Chen and Silverstein 2000; Shi 1993; Xu and Yuan 1997; Yuan 1987). Sons and daughters-inlaw have traditionally been the main care-givers for old parents, while daughters' contributions have been lower. However, in the last decade the genderbased exchange contract between parents and adult children has lost its importance in urban China due to the fundamental changes in the economic structure, culture and social system in urban areas (Lei 2013).

Nowadays, rapid economic growth and migration in China have jeopardised the ability of the family to serve as a resource to its older members; adults go to urban areas to work and live, while their old parents continue to live in rural areas, and the number of empty-nest families continues to rise (Liu and Guo 2007; Wang and Zhao 2011). Although children still serve as the primary source of support for their parents (Chen and Silverstein 2000; Gu et al. 1995), the dynamics of parent-child relationships are undergoing a dramatic transition in China (Chen and Silverstein 2000). 


\section{Intergenerational relationships and life satisfaction in different cultural contexts}

Moreover, the association between intergenerational relationships and life satisfaction is shaped by the cultural context. Namely cultural factors may also exert a significant influence on life satisfaction (Suh et al. 1998). One important finding is that subjective wellbeing, which refers to the degree of satisfaction people experience in their lives, tends to be higher in individualist cultures than in collectivist cultures (Diener, Diener and Diener 1995; Rice and Steele 2004; Schyns 1998; Veenhoven 1997). In collectivist cultures a person's life satisfaction may be derived much more from his or her in-group (e.g. family, friends and co-workers) (Diener and Diener 1995; Triandis 1989), but in individualist cultures a person's subjective wellbeing is best predicted by the attainment of personal goals and high self-esteem or self-efficacy (Uchida and Ogihara 2012). Thus, in more collectivistic cultures, such as China and Russia, the association between relationship quality and life satisfaction might be stronger than in Germany, which could be described as a more individualistic country.

The influence of the cultural context reveals norms and attitudes regarding filial obligations (e.g. normative solidarity), which do not necessarily directly translate into actual care provision but may generate the motivation to provide care and support (Daatland and Herlofson 2003; Moor and Komter 2008). For instance, the traditional Chinese culture of filial piety towards old parents ( $\mathrm{Ng} \mathrm{2002)} \mathrm{might,} \mathrm{in} \mathrm{part,} \mathrm{shed} \mathrm{new} \mathrm{light} \mathrm{on} \mathrm{mitigating} \mathrm{negative}$ attitudes towards older people. As a result, it is worth examining whether family relations might exert influence on old people's life satisfaction in diverse cultures. Therefore, an attempt is made to test whether the associations between relationship quality, life satisfaction and satisfaction with family life have the same pattern in different cultural contexts, comparing a Confucian culture in China with a Western culture (Germany) and with Russia and Estonia, which are under the influence of the former Soviet Union.

Moreover, it is assumed that there are some differences in the strength of these associations across countries. It is also intended to provide an estimate for the direct effect of the relationship quality on the level of life satisfaction and to examine whether the effect is mediated by satisfaction with family life. Following Kagitcibasi's Family Change Theory (2007), these countries represent different ideal-typical family models. Kagitcibasi has distinguished the dimension of a culture of separateness (individualism) from the dimension of a culture of relatedness (collectivism). According to her approach, Germany represents a family model of independence, whereby autonomy is valued highly and material interdependence is valued relatively 
lowly (Kagitcibasi, Ataca and Diri 2010; Mayer 2013). The first hypothesis assumes that the relationship quality has influence on general life satisfaction in Germany. This is in accordance with recent studies which have indicated that emotional closeness between generations is still relatively high in Western families (Mayer 2013).

Russia and China could be described as countries where the family model of emotional interdependence still prevails, but the norms-related obligations still dominate in intergenerational relations (Chen and Silverstein 2000). Thus, the second hypothesis assumes that in Russia and China there is no strong association between relationship quality and life satisfaction. Regarding Estonia, on the one hand, the expectation of autonomy is growing while, on the other hand, the wish to maintain the importance of family loyalty, integrity and close-knit ties remains; the latter is especially true from the point of view of the older generation. It is hypothesised that, in this transitional context, the older mothers' life satisfaction is particularly influenced by their actual relationship with their adult daughters. The final hypothesis states that in these four countries the older mothers' life satisfaction is not directly linked to the perceived relationship quality with their adult daughters, but is mediated by the older mothers' satisfaction with family life.

\section{Method}

\section{Participants}

The cross-cultural VOC (Value of Children and Intergenerational Relations) study comprised three generations: older mothers, adult daughters and an adolescent child of the daughters (Trommsdorff and Nauck 2005). The selection processes of the respondents of the VOC study were as follows: first, the $14^{-1}$-year-old adolescents were contacted randomly and asked if they and their mothers would like to participate in the survey. After obtaining consent, the adolescents and their mothers were interviewed by investigators and then were asked further if the grandmothers would like to participate. Two situations occurred: (a) the mothers did not agree to the participation of the grandmothers; or (b) the grandmothers had died. If the consent of the mothers was obtained, the grandmothers were contacted by investigators and were requested to give their consent to participation. As refusals by a certain number of grandmothers had been predicted, the VOC study was designed to ensure that at least 100 grandmothers would participate. This study, which involved only the grandmothers, explored the relationship between the older mothers and their adult daughters. 
In Estonia, the sample was recruited through random selection of residential addresses from 11 counties and the two largest cities (Tallinn and Tartu) in 2009. In Germany, the sample was recruited through searching residents' registration offices from three different cities (Chemnitz, Essen and Konstanz) in 2002. In Russia, the sample was recruited through the vocational and secondary schools of the adolescents in the region of Nishnij Nowgorod in 2006 and 2007. In China, the sample was recruited through the schools of adolescents and through selection from inhabitant lists of neighbourhood committees in four regions, Beijing Municipality, Henan Province, Yunnan Province and Guangxi Zhuang Autonomous Region, in 2003. The samples comprised respondents from both urban and rural areas in Estonia, Russia and China, but in Germany the respondents were solely from urban areas. A detailed description of the data sources is given elsewhere (Mayer et al. 2005; Schwarz et al. 2010b; Zheng, Shi and Tang 2005).

The number of those interviewed is as follows: 114 Estonian older mothers, 99 German older mothers, 83 Russian older mothers and 207 Chinese older mothers. The following indicators were used: quality of relationship between older mothers and their adult daughters, satisfaction with family life and life satisfaction. Older mothers in the study had more than one daughter: Estonian older mothers had an average of two children, German older mothers had an average of three children, Russian older mothers had an average of two children and Chinese older mothers had an average of four children. These older mothers only estimated the relationship with the adult daughter who also participated in the study.

The questionnaires were translated from the original English version into the respective target language by a bilingual native speaker of the target language. The questionnaires were then back translated and inconsistencies were corrected in co-operation with the translators from the respective cultures. Moreover, most of the instruments chosen in the study had already been tested in other cross-cultural studies (see Trommsdorff et al. 2002).

\section{Measures}

Given that relationship quality is subjective and individual, its measurement must be rooted in the perceptions of each respondent (Litwin and ShiovitzEzra 2006) and a person's perception is at least as important as the actual circumstances for wellbeing and behaviour (Bronfenbrenner 1979; Schwarz 2006); therefore, the older mothers were asked how they perceived their respective relationships with their adult daughters.

Quality of relationship between older mothers and their adult daughters. The quality of relationship measure is based on Fuhrman and Buhrmester's 
(1985) Network of Relationships Inventory instrument. The subscales admiration, conflict and intimacy were chosen for the VOC study. Admiration (three items: A - 'How often does your daughter/mother let you know that you are good at many things?', B - 'How often does your daughter/mother like or approve of the things you do?', C- 'How often do you feel that your daughter/mother admires you?'); conflict (three items: D - 'How often do you and your daughter/mother disagree and quarrel?', E- 'How often do you and your daughter/mother argue with each other?', F- 'How often do you and your daughter/mother get upset with or mad at each other?'); and intimacy (three items: G- 'How often do you tell your daughter/mother everything that is on your mind?', $\mathrm{H}$ - 'How often do you share your secrets and private feelings with your daughter/mother', I - 'How often do you talk to your daughter/ mother about things that you do not want others to know?'). All items were rated on a five-point scale ( 1 =never to 5 =always). Reliabilities were calculated for those variables. The internal consistencies for relationship quality dimensions (Cronbach's alpha) were as follows: the internal consistency for admiration was lowest in Germany $(\alpha=0.71)$ and highest in China $(\alpha=0.77)$; the internal consistency for conflict was lowest in Germany $(\alpha=0.73)$ and highest in China $(\alpha=0.83)$; the internal consistency for intimacy was lowest in China $(\alpha=0.74)$ and highest in Germany $(\alpha=0.81)$.

Life satisfaction and satisfaction with family life. To assess general life satisfaction, one item from the well-approved Satisfaction with Life Scale was used (Diener et al. 200o). In addition, four items referring to specific aspects of participants' life were collected (Henrich and Herschbach 1995) and one of the items - satisfaction with family life - was selected for the study. Life satisfaction was assessed by the following question: 'All things considered, how satisfied are you with life as a whole these days?' To measure satisfaction with family life, the following question was used: 'How satisfied are you with your family?' Both items were rated on a fivepoint scale $(1=$ not satisfied at all to $5=$ very satisfied $)$.

\section{Data analysis}

The study aimed to develop and test a Structural Equation Model of relationship quality, satisfaction with family life and life satisfaction. Confirmatory factor analysis was used to test the measurement model and path analyses were conducted to examine the hypothesised relationships between all variables. The model was estimated via the maximum likelihood using the Analysis of Moment Structures (AMOS 20). Structural Equation 
Modelling is particularly suited to testing mediators because it permits the simultaneous estimation of direct and indirect paths. The aim was to analyse each path after the effects of all other paths had been accounted for. The model contained three latent variables, admiration, conflict and intimacy, as measures of relationship quality which predicted satisfaction with family life and general life. The relationship quality dimensions predicted both types of satisfaction and it was assumed that satisfaction with family life mediated the effect of relationship quality on general life satisfaction. The latent constructs were represented by observed scores on the relationship quality scales described in the Measures section. Covariance was permitted among the latent variables. A multiple group comparison approach was used to test the configural invariance between the four countries by means of a model without constraints. The model fit was assessed with the chisquare statistic $\left(\chi^{2}\right)$, which is a significance test of the null hypothesis that the model fits the data perfectly. Due to sample size differences, the relative chi-square statistics were calculated. The Comparative Fit Index (CFI), the Tucker-Lewis Index (TLI) and the Root Mean Square Error of Approximation (RMSEA) were applied to assess the model fit. The RMSEA indicates a very good fit with the data if it is close to zero. According to $\mathrm{Hu}$ and Bentler (1999), the acceptable recommended fit is below o.o6; with regard to the CFI, values over o.go indicate a good model fit.

\section{Results}

The mean age of the Estonian older mothers was 67.0 (standard deviation $(\mathrm{SD})=7.8)$ and adult daughters was $41.4(\mathrm{SD}=6.0)$; the mean age of the German older mothers was $69.6(\mathrm{SD}=5.9)$ and adult daughters was 43.5 $(\mathrm{SD}=4.9)$; the mean age of the Russian older mothers was $67.5(\mathrm{SD}=7.4)$ and adult daughters was $41.1(\mathrm{SD}=5 \cdot 7)$. The mean age of Chinese older mothers was 66.3 $(\mathrm{SD}=5.9)$ and adult daughters was $39.6(\mathrm{SD}=4.0)$. The Chinese older mothers and adult daughters were significantly younger than all the other sub-samples by a one-way analysis of variance. All older mothers came from urban and rural areas, except for those from the German sample. Almost all older mothers received education, except for those from the Chinese sample. The socio-demographic information of the older mothers in these four countries is presented in Table 1. In the Estonian sample, 36.0 per cent of the older mothers were married and 28.1 per cent were widowed. In the German sample, 50.o per cent of the older mothers were married and 39.8 per cent were widowed. In the Russian sample, 24.1 per cent of the older mothers were married and 63.9 per cent were widowed. Among the older mothers from China, $6_{5.2}$ 
TAB LE 1. Socio-demographic characteristics of older mothers in Estonia, Germany, Russia and China

\begin{tabular}{lrcrr}
\hline Characteristic & Estonia & Germany & Russia & China \\
\hline Region: & \multicolumn{4}{c}{ Percentages } \\
$\quad$ Urban & 71.1 & 100.0 & 70.7 & 46.4 \\
$\quad$ Rural & 28.9 & 0.0 & 29.3 & 53.6 \\
Education: & & & & \\
$\quad$ Schooling & 100.0 & 97.0 & 100.0 & 61.8 \\
$\quad$ No schooling & & 3.0 & & 38.2 \\
Household: & & & & \\
$\quad$ Living alone & 37.7 & 42.9 & 7.6 & 12.7 \\
$\quad$ Living with others & 62.3 & 57.1 & 92.4 & 87.3 \\
Marital status: & & & & \\
$\quad$ Single & 7.0 & & 1.2 & \\
$\quad$ Married (first marriage) & 36.0 & 50.0 & 24.1 & 65.2 \\
$\quad$ Remarried & 9.6 & 3.1 & 3.6 & 1.4 \\
$\quad$ Widowed & 28.1 & 39.8 & 63.9 & 32.9 \\
$\quad$ Separated & 1.8 & & 1.2 & \\
$\quad$ Divorced & 17.5 & 7.1 & 6.0 & 0.5 \\
Employment (Do you have a job currently?): & & & & \\
$\quad$ Yes & 36.0 & 14.3 & 14.6 & 10.3 \\
$\quad$ No & 64.0 & 85.7 & 85.4 & 89.7 \\
&
\end{tabular}

per cent were married and 32.9 per cent were widowed. All others were single, remarried, separated or divorced.

As shown in Table 2, Estonian older mothers reported the least admiration $($ mean $=2.4)$ and intimacy $($ mean $=2.6)$ in their relationships with their adult daughters. German older mothers perceived the most admiration from their adult daughters $($ mean $=3.2)$ compared to Estonian, Russian and Chinese older mothers. Russian older mothers reported the most conflict $($ mean $=2.1)$ and intimacy $($ mean $=3.4)$ with their adult daughters among the four countries. In sum, Estonian older mothers reported the least satisfaction with their family (mean $=4.0$ ) and Russian older mothers reported the least general life satisfaction $($ mean $=3.5)$; German older mothers were most satisfied with their family life $($ mean $=4.4)$ and with general life $($ mean $=4 \cdot 3)$.

In the Estonian sample, the perceptions of conflict $(-0.24, p<0.05)$ and intimacy $(0.26, p<0.01)$ were significantly correlated with the older mothers' satisfaction with family life (Table 3). In the German sample, the perception of admiration was significantly correlated with the older mothers' satisfaction with family life $(0.27, p<0.01)$. In the Russian sample, all variables had a significant correlation with the older mothers' 
T A B LE 2. Means and standard deviations (SD) for relationship quality between the older mothers and adult daughters, satisfaction with family life and life satisfaction, separately for the Estonian, German, Russian and Chinese samples

\begin{tabular}{|c|c|c|c|c|c|c|c|c|c|}
\hline & \multicolumn{2}{|c|}{ Estonia } & \multicolumn{2}{|c|}{ Germany } & \multicolumn{2}{|c|}{ Russia } & \multicolumn{2}{|c|}{ China } & \multirow{2}{*}{$\begin{array}{l}\text { One-way } \\
\text { ANOVA }\end{array}$} \\
\hline & Mean & $\mathrm{SD}$ & Mean & SD & Mean & SD & Mean & SD & \\
\hline Admiration & 2.4 & 0.7 & 3.2 & 0.8 & 3.0 & 0.8 & 2.7 & 1.0 & $\begin{array}{l}\text { Estonia }<\text { all; } \\
\text { Germany }>\text { all }\end{array}$ \\
\hline Conflict & 1.9 & o.6 & 1.5 & 0.5 & 2.1 & 0.7 & 1.6 & 0.7 & $\begin{array}{c}\text { Germany }<\text { all; } \\
\text { Russia }>\text { all }\end{array}$ \\
\hline Intimacy & 2.6 & 0.8 & 2.9 & 0.9 & $3 \cdot 4$ & 0.9 & 2.7 & 1.0 & $\begin{array}{c}\text { Estonia }<\text { all; } \\
\text { Russia }>\text { all }\end{array}$ \\
\hline $\begin{array}{l}\text { Satisfaction with } \\
\text { family life }\end{array}$ & 4.0 & o.6 & $4 \cdot 4$ & o.6 & $4 \cdot 2$ & 0.7 & $4 \cdot 1$ & 0.9 & $\begin{array}{l}\text { Estonia }<\text { all; } \\
\text { Germany }>\text { all }\end{array}$ \\
\hline Life satisfaction & $3 \cdot 7$ & 0.7 & $4 \cdot 3$ & 0.7 & $3 \cdot 5$ & 0.8 & $3 \cdot 9$ & 0.8 & $\begin{array}{c}\text { Russia }<\text { all; } \\
\text { Germany }>\text { all }\end{array}$ \\
\hline
\end{tabular}

Notes: Admiration (three items: A - 'How often does your daughter/mother let you know that you are good at many things?', B - 'How often does your daughter/mother like or approve of the things you do?', C- 'How often do you feel that your daughter/mother admires you?'), conflict (three items: D- 'How often do you and your daughter/mother disagree and quarrel?', E- 'How often do you and your daughter/mother argue with each other?', F- 'How often do you and your daughter/mother get upset with or mad at each other?') and intimacy (three items: $\mathrm{G}$ - 'How often do you tell your daughter/mother everything that is on your mind?', $\mathrm{H}$ - 'How often do you share your secrets and private feelings with your daughter/mother', I - 'How often do you talk to your daughter/mother about things that you do not want others to know?'). All items were rated on a five-point scale $(1=$ never to 5 =always). Satisfaction with family life: 'How satisfied are you with your family?' Life satisfaction: 'All things considered, how satisfied are you with life as a whole these days?' Both items were rated on a five-point scale $(1=$ not satisfied at all to $5=$ very satisfied $)$.

satisfaction with family life. In the Chinese sample, the perceptions of admiration $(0.19, p<0.01)$ and intimacy $(0.20, p<0.01)$ had a significant correlation with the older mothers' satisfaction with family life.

The Structural Equation Model was presented for older mothers in four countries (Figure 1). In constructing the model, it was conceptualised that the relationship quality contributed directly and indirectly to life satisfaction. This model demonstrates that the impact of relationship quality on general life satisfaction was mediated through satisfaction with family life. The results of multi-group comparisons applying the same structural model and assuming identical relations between the latent constructs for all four countries and free estimates for all other relations evinced acceptable fits. All indices showed that the model fitted well with the data $\left(\chi^{2}=\right.$ $253.14, \mathrm{df}=144, p=0.000 ; \chi^{2} / \mathrm{df}=1.76$; RMSEA $=0.03$; CFI = 0.93). It indicated that there were no significant differences between the structural relations in the four countries. 
1284 Jing Wu et al.

T A B LE 3. Pearson correlation coefficients of the variables for older mothers in Estonia, Germany, Russia and China

\begin{tabular}{|c|c|c|c|c|c|}
\hline & Country & 1 & 2 & 3 & 4 \\
\hline \multirow[t]{4}{*}{ 1. Admiration } & Estonia & 1 & -0.08 & $0.5^{0 * *}$ & 0.08 \\
\hline & Germany & 1 & $-0.24^{*}$ & $0.61 * *$ & $0.27 * *$ \\
\hline & Russia & 1 & $-0.24^{*}$ & $0.57^{* *}$ & $0.29 *$ \\
\hline & China & 1 & $-0.18^{*}$ & $0.31^{* *}$ & $0.19^{* *}$ \\
\hline \multirow[t]{4}{*}{ 2. Conflict } & Estonia & & 1 & -0.17 & $-0.24^{*}$ \\
\hline & Germany & & 1 & 0.02 & -0.15 \\
\hline & Russia & & 1 & -0.18 & $-0.28^{*}$ \\
\hline & China & & 1 & -0.02 & -0.10 \\
\hline \multirow[t]{4}{*}{ 3. Intimacy } & Estonia & & & 1 & $0.26^{* *}$ \\
\hline & Germany & & & 1 & 0.18 \\
\hline & Russia & & & 1 & $0.27^{*}$ \\
\hline & China & & & 1 & $0.20^{* *}$ \\
\hline \multirow{4}{*}{$\begin{array}{l}\text { 4. Satisfaction with } \\
\text { family life }\end{array}$} & Estonia & & & & 1 \\
\hline & Germany & & & & 1 \\
\hline & Russia & & & & 1 \\
\hline & China & & & & 1 \\
\hline
\end{tabular}

Significance levels: $* p<0.05, * * p<0.01$.

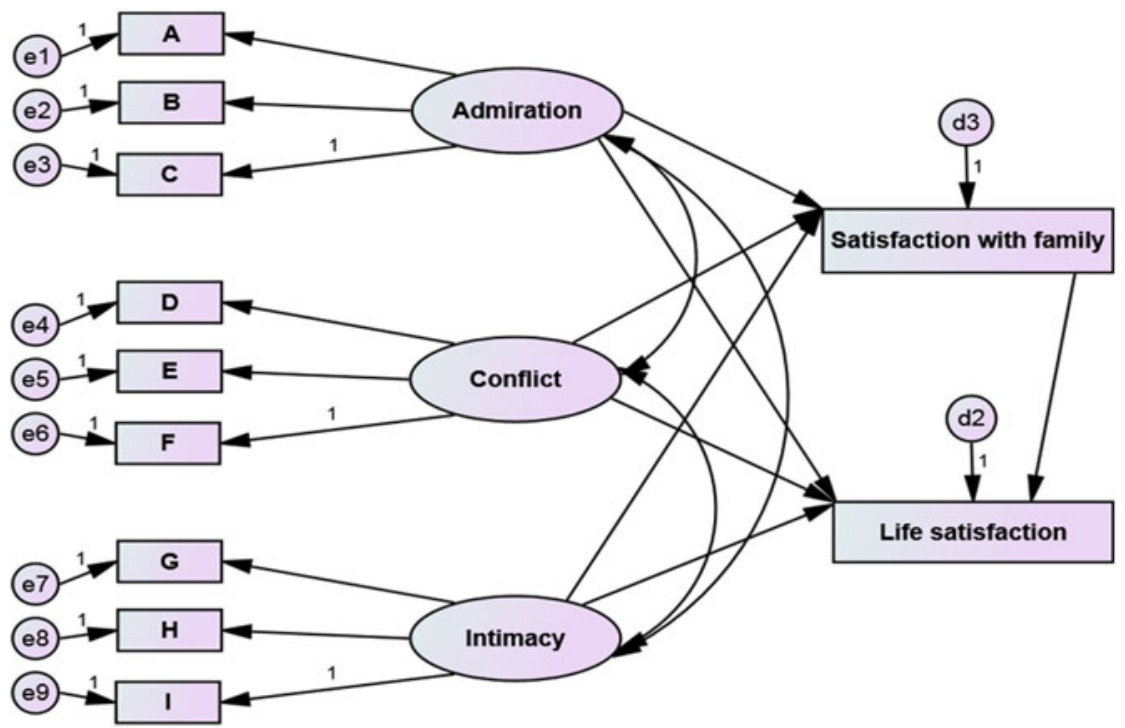

Figure 1. Structural Equation Model of relationship quality, life satisfaction and satisfaction with family life among older mothers in Estonia, Germany, Russia and China.

Notes: For details of A-I, see Table 2. d2, d3: disturbances, e1-eg: error terms, 1: a metric for each latent factor. Model-fit indices: $\chi^{2}=253.14, \mathrm{df}=144, p=0.000 ; \chi^{2} / \mathrm{df}=1.76$. Root Mean Square Error of Approximation = o.o3. Comparative Fit Index $=0.93$. 
T A B L 4 . Standardised total and direct effects of variables on life satisfaction of older mothers in Estonia, Germany, Russia and China

\begin{tabular}{|c|c|c|c|c|}
\hline & Estonia & Germany & Russia & China \\
\hline Total effect of admiration on life satisfaction & 0.14 & 0.54 & $0.4^{2}$ & $0.14^{*}$ \\
\hline Total effect of conflict on life satisfaction & -0.31 & 0.07 & -0.17 & -0.19 \\
\hline Total effect of intimacy on life satisfaction & -0.01 & -0.23 & $-0.3^{8}$ & $-0.03^{*}$ \\
\hline $\begin{array}{l}\text { Direct effect of admiration on satisfaction with } \\
\text { family life }\end{array}$ & -0.14 & 0.23 & 0.24 & 0.12 \\
\hline $\begin{array}{l}\text { Direct effect of conflict on satisfaction with } \\
\text { family life }\end{array}$ & $-0.21 \dagger$ & -0.10 & -0.18 & $-0.16^{*}$ \\
\hline $\begin{array}{l}\text { Direct effect of intimacy on satisfaction with } \\
\text { family life }\end{array}$ & $0.35^{*}$ & 0.04 & 0.09 & $0.24^{* *}$ \\
\hline Direct effect of admiration on life satisfaction & 0.19 & 0.47 & $0.39^{\dagger}$ & 0.09 \\
\hline Direct effect of conflict on life satisfaction & $-0.25^{*}$ & 0.11 & -0.15 & $-0.12 \dagger$ \\
\hline Direct effect of intimacy on life satisfaction & -0.12 & -0.24 & $-0.39^{\dagger}$ & -0.13 \\
\hline $\begin{array}{l}\text { Direct effect satisfaction with family life on life } \\
\text { satisfaction }\end{array}$ & $0.31^{* * *}$ & $0.31^{* *}$ & 0.13 & $0.42^{* * *}$ \\
\hline
\end{tabular}

Significance levels: $\dagger p<0.1, * p<0.05, * * p<0.01, * * * p<0.001$.

The Structural Equation Model tested the total and direct effects of the three dimensions of relationship quality and satisfaction with family life on life satisfaction in four countries (see Table 4). The Estonian sample indicates that satisfaction with family life has a weak negative association with conflict $(-0.21, p<0.1)$ and a positive association with intimacy $(0.35, p<0.05)$. The Chinese sample demonstrates that satisfaction with family life is negatively influenced by conflict $(-0.16, p<0.05)$ and positively influenced by intimacy $(0.24, p<0.01)$. The variables of relationship quality with adult daughters had no statistically significant influence on older mothers' satisfaction with family life either in the German sample or in the Russian sample. General life satisfaction was negatively associated with conflict among Estonian older mothers $(-0.25, p<0.05)$. In the Russian sample, general life satisfaction of older mothers was positively associated with admiration (0.39) and negatively associated with intimacy $(-0.39)$, although these effects are significant at the 0.1 level.

The relationship between satisfaction with family life and life satisfaction was statistically significant in all countries except in Russia. Hence, higher satisfaction with family life contributed to higher satisfaction with general life, and an especially strong association was revealed in the Chinese sample. As indicated in the results, the total effect of admiration (except Estonia) was stronger when the indirect effect mediated by satisfaction with family life was taken into account. Moreover, the total effects of conflict on general life satisfaction in Estonia, Russia and China were 
higher, compared to the direct effects of conflict. Thus, satisfaction with family life would strengthen the positive and negative aspects of intergenerational relationships on life satisfaction of older mothers.

\section{Discussion}

The present study has made an important contribution to the question of the role of older mother-adult daughter relationships for older mothers' life satisfaction across diverse cultures. It demonstrates that the cultural values of individualism and collectivism should be taken into account in order to improve the understanding of the conditions and consequences of intergenerational relationships (Trommsdorff and Mayer 2012). Trommsdorff and Schwarz (2007) propose that self-disclosure is a more relevant communication style in individualistic cultures than in collectivistic cultures. High self-disclosure by mothers in their relationship with their daughters might be a less acceptable behaviour in collectivistic cultures, where clear role definitions and hierarchical role differentiation regulate interactions. The more the mothers prefer collectivistic values, the higher the probability that the mother-daughter dyad will be characterised by the pattern with less maternal self-disclosure (Trommsdorff and Schwarz 2007). The results of the present study are in line with this theoretical approach. Estonian older mothers perceived the least intimacy with their adult daughters among all the respondents of the four countries. It is characteristic of Estonian culture for parents to take care of their children and children to look after their old parents (Laidmäe, Tulva and Sepp 2009). This tradition can be regarded as part of collectivistic value orientation. Older people constitute an important resource in family life, e.g. the older people who continue working support their adult children more financially than those who only receive their pensions (Laidmäe et al. 2011). The present study also shows that compared to older mothers from the other cultures, German older mothers perceived the most admiration from their adult daughters and the least conflict with their daughters. German parent-child relationships are negotiated according to individual goals and interests in the context of the individualistic organisation of family relationships (Trommsdorff and Schwarz 2007). The separation of family members' residences may decrease the opportunity for personal interaction, while it also reduces the likelihood of interpersonal conflict (Hwang 1999). Moreover, the results revealed that the most conflict and intimacy were perceived by Russian older mothers compared to those of other countries. Mothers and daughters communicate with each other directly (Fingerman 1996; Troll and Smith 1976) and they claim to experience 
greater tension as well as greater intimacy in their relationships (Fingerman 1996; Lehr 1984; Troll 1987).

The Structural Equation Modelling analysis was used to test whether older mothers' life satisfaction and satisfaction with family life were associated with relationship quality in the four countries. Firstly, general life satisfaction of older mothers was strongly related to satisfaction with family life in Estonia, Germany and China, but not in Russia. Previous studies (see Dolan, Peasgood and White 2008) have shown that subjective wellbeing is determined by several factors: personal characteristics, socially developed characteristics, attitudes and beliefs, the wider economic, social and political environment, and relationships, etc. Satisfaction with family life represents only one influential factor: the general estimation of relationships with family members. Apparently, in Russia, the other determinants of wellbeing were more dominant than family relations. This is in line with a previous study by Saris (2001), which states that due to financial uncertainty people in Russia are concerned with this domain, which also determines their subjective wellbeing more than family life and marriage do.

Secondly, satisfaction with family life was significantly associated with intergenerational relationship quality in Estonia and China. In the Estonian context, the older mothers' satisfaction with family life was particularly influenced by the relationship quality with their adult daughters. The results of the German sample contradicted our hypothesis that relationship quality with adult daughters influences older mothers' life satisfaction or satisfaction with family life. It is in line with the conclusions of the Family Change Theory that family relations might be relatively more distant in the West when one takes a global perspective and contrasts Western families with those in most other parts of the world (Mayer 2013).

As for the Russian and Chinese cases, according to our original hypothesis, there was no strong association between emotional closeness, life satisfaction and satisfaction with family life due to dominant norms, obligations and filial obligations in intergenerational relations (Chen and Silverstein 200o); however, the findings of the Chinese sample contradicted the hypothesis. Chinese older mothers' satisfaction with family life was associated with their perceptions of the relationship quality with their adult daughters. In Chinese society, the Confucian teaching of filial piety commands young people to be respectful, caring and obedient to older people, family or otherwise (Ho 1994; Sung 1995; Yue and Ng 1999). These values have been instilled into children's belief systems through socialisation processes and parents' early investment in their development process (Lin and Fu 1990; Sun 2002; Yang 1996). Even though social and economic changes might be unfavourable to intergenerational cohesion and the maintenance of filial behaviours (Yue and $\mathrm{Ng}$ 1999), filial piety is still regarded as an 
important virtue, which is presented as filial attitudes in Chinese society (Chen, Bond and Tang 2007).

Thirdly, satisfaction with family life mediated the influence of admiration and conflict on general life satisfaction. Even though the mediating role of family life satisfaction was relatively low considering the sizes of the total and direct effects, Structural Equation Modelling demonstrated that satisfaction with family life would strengthen the positive effect of admiration and the negative effect of conflict on the general life satisfaction of older mothers. To some extent, this supports the previous findings that satisfaction with family relations and with family members influences older persons' life satisfaction (Albert, Labs and Trommsdorff 2010; Diener and Diener McGavran 2008; Schwarz et al. 2005, $2010 a$ ).

More interestingly, the results showed that intimacy was positively associated with family life satisfaction but negatively associated with general life satisfaction, a pattern which existed in all four countries. The possible explanations would be that the items of intimacy, such as sharing private feelings and secret talks between older mothers and adult daughters, to some extent might reflect their contact frequency and emotional closeness; this in turn might strengthen older mothers' perception of satisfaction with family relations and with family members. However, since older mothers and adult daughters who claim to experience greater intimacy also perceive greater tensions in their relationships (Fingerman 1996; Lehr 1984; Troll 1987), intimacy might generate negative perceptions of the general life satisfaction of older mothers.

The limitations of the measures must be considered in relation to the findings of the study. At the societal level, it was impossible to include designated socio-economic factors into the analyses to examine the effects of welfare regimes and socio-economic transitions on family relations in the four countries. Moreover, it was impossible to compare the differences of the older mother-adult daughter relationships and satisfaction with life and family in urban and rural areas of the four countries due to the lack of rural samples from Germany. Satisfaction in other life domains (e.g. partners, friends, work, health, etc.) were not taken into consideration since the family domain was the only focus of this study for theoretical reasons.

Nevertheless, the present study provides an insight into similarities and differences in older mother-adult daughter relationships in the diverse cultural contexts of Estonia, Germany, Russia and China. This contribution to the VOC study provides further evidence to support the concept that the intergenerational relationships in families during the processes of transition and globalisation play an important role in the life satisfaction of older mothers. Therefore, future research in terms of transitional countries 
should take into consideration not only micro-level indicators, such as emotional closeness and intergenerational relationships, but also macro-level indicators, such as social and cultural transition and modernisation.

\section{Acknowledgements}

The data collection in Estonia received funding from the European Social Fund measure 1.4 'Enhancing Administrative Capacity', administrated by the Structural Fund Unit of the State Chancellery. The study was also supported by the University of Tartu (Rector's Science Foundation Grant) and the Estonian Research Council (PUT-499). In Germany, Russia and China the data collection was supported by a grant from the German National Science Foundation (Deutsche Forschungsgemeinschaft for the study 'Value of Children and Intergenerational Relations'; the principal investigators were Prof. Dr Gisela Trommsdorff from the University of Konstanz, Germany and Prof. Dr Bernhard Nauck from Chemnitz University of Technology, Germany; team leaders were Dr Kairi Kasearu from the University of Tartu, Estonia, Prof. Dr Zaretkhan Kh.-M. Saralieva from the University of Nishni Novgorod, Russia and Prof. Dr Gang Zheng from the Chinese Academy of Sciences, China).

\section{References}

Albert, I., Labs, K. and Trommsdorff, G. 2010. Are older adult German women satisfied with their lives? On the role of life domains, partnership status, and self-construal. Journal of Gerontopsychology and Geriatric Psychiatry, 23, 1, 39-49.

Albertini, M., Kohli, M. and Vogel, C. 2007. Intergenerational transfers of time and money in European families: common patterns, different regimes? Journal of European Social Policy, 1 7, 4, 319-34.

Bodner, E. and Cohen-Fridel, S. 2010. Relations between attachment styles, ageism and quality of life in late life. International Psychogeriatrics, 22, 8, 1353-61.

Bond, M. H. 1991. Beyond the Chinese Face: Insights from Psychology. Oxford University Press, Hong Kong.

Bronfenbrenner, U. 1979. The Ecology of Human Development: Experiments by Nature and Design. Harvard University Press, Cambridge, Massachusetts.

Chen, X.H.S., Bond, M.H. and Tang, D.H. 2007. Decomposing filial piety into filial attitudes and filial enactments. Asian Journal of Social Psychology, 1o, 4, $213^{-23}$.

Chen, X. and Silverstein, M. 200o. Intergenerational social support and the psychological well-being of older parents in China. Research on Aging, 22, 1, $43-65$.

Daatland, S. O. and Herlofson, K. 2003. 'Lost solidarity' or 'changed solidarity': a comparative European view of normative family solidarity. Ageing $\mathcal{E}$ ' Society, 23, 5, 537-6o.

Diener, E. and Diener, M. 1995. Cross-cultural correlates of life satisfaction and selfesteem. Journal of Personality and Social Psychology, 68, 4, 653-63.

Diener, E., Diener, M. and Diener, C. 1995. Factors predicting the subjective wellbeing of nations. Journal of Personality and Social Psychology, 69, 5, 851-64. 
Diener, E., Gohm, C. L., Suh, E. and Oishi, S. 2000. Similarity of the relations between marital status and subjective well-being across cultures. Journal of Crosscultural Psychology, 31, 4, 419-36.

Diener, M. L. and Diener McGavran, M. B. 2008. What makes people happy? A developmental approach to the literature on family relationships and well-being. In Larson, R. and Eid, M. (eds), The Science of Subjective Well-being. Guilford, New York, $347-75$.

Dolan, P., Peasgood, T. and White, M. 2008. Do we really know what makes us happy? A review of the economic literature on the factors associated with subjective well-being. Journal of Economic Psychology, 29, 1, 94-122.

Dykstra, P. A. 2010. Intergenerational Family Relationships in Ageing Societies. United Nations Economic Commission for Europe, New York.

Fingerman, K. L. 1996. Sources of tension in the aging mother and adult daughter relationship. Journal of Psychology and Aging, 1 1, 4, 591-6o6.

Fingerman, K. L. 2001. Aging Mothers and Their Adult Daughters: A Study in Mixed Emotions. Springer, New York.

Furman, W. and Buhrmester, D. 1985. Children's perceptions of the personal relationships in their social networks. Developmental Psychology, 2 1, 6, 1016-24.

Gerber, T. P. and Berman, D. 2010. Entry to marriage and cohabitation in Russia, 1985-2000: trends, correlates and impacts of the second demographic transition. European Journal of Population, 26, 1, 3-31.

Gu, S.Z., Zhu, N., Chen, X.G. and Liang, J. 1995. Old-age support system and policy reform in China. Korea Journal of Population and Development, 24, 2, $245^{-73}$.

Henrich, G. E. and Herschbach, P. 1995. Fragen zur Lebenszufriedenheit (FLZ) ein Gewichtungsmodell [Questions on life satisfaction. A weighting model.] In Schwarz, R., Bernhard, J., Flechtner, H., Küchler, T. and Hürny, C. (eds), Lebensqualität in der Onkologie. Zuckerschwerdt Verlag, München.

Ho, D. Y.-F. 1994. Filial piety, authoritarian moralism, and cognitive conservatism in Chinese societies. Genetic, Social, and General Psychology Monographs, 12o, 3, $347-65$.

Hofstede, G. H. 1991. Culturals and Organizations: Software of the Mind. McGraw-Hill, London.

Hu, L. and Bentler, P. M. 1999. Cutoff criteria for fit indexes in covariance structure analysis: conventional criteria versus new alternatives. Structural Equation Modeling, $6,1,1-55$.

Hwang, K.-K. 1999. Filial piety and loyalty: two types of social identification in Confucianism. Asian Journal of Social Psychology, 2, 1, 163-83.

Inglehart, R. and Welzel, C. 2005. Modernization, Cultural Change, and Democracy: The Human Development Sequence. Cambridge University Press, New York.

Kagitcibasi, C. 2007. Family, Self, and Human Development Across Cultures: Theory and Applications. Second edition, Erlbaum, Hillsdale, New Jersey.

Kagitcibasi, C., Ataca, B. and Diri, A. 2010. Intergenerational relationships in the family: ethnic, socioeconomic, and country variations in Germany, Israel, Palestine, and Turkey. Journal of Cross-cultural Psychology, 41 , 5/6, 652-70.

Kasearu, K. and Kutsar, D. 2010. Informal support networks in a changing societyare family-based networks being 'crowded-out'? Studies of Transition States and Societies, 2, 2, 56-73.

Kasearu, K. and Kutsar, D. 2013. Intergenerational solidarity in families: interplay between the family and the state. In Albert, I. and Ferring, D. (eds), Intergenerational Relations. European Perspectives on Family and Society. Policy Press, Bristol, UK, $25^{-3} 8$. 
Künemund, H. 2008. Intergenerational relations within the family and the state. In Saraceno, C. (ed.), Families, Ageing and Social Policy: Intergenerational Solidarity in European Welfare States. Edward Elgar Publishing, Cheltenham, UK, $105^{-22 .}$

Laidmäe, V.-I., Hansson, L., Leppik, L., Tulva, T. and Lausvee, E. 2011 . Later life in Estonia: satisfaction with life and intergenerational support. The Internet Journal of Geriatrics and Gerontology, 6, 1. Available online at http://archive.ispub.com/ journal/the-internet-journal-of-geriatrics-and-gerontology/volume-6-number-1/laterlife-in-estonia-satisfaction-with-life-and-intergenerational-support.html\#sthash.eoooiDCb. dpbs.

Laidmäe, V.-I., Hansson, L., Tulva, T., Lausvee, E. and Kasepalu, Ü. 2010. Multi-generation family in Estonia: multiple roles and the stress of living together with elderly people. The Internet Journal of Geriatrics and Gerontology, 5, 2. Available online at http://archive.ispub.com/journal/the-internet-journal-of-geriatricsand-gerontology/volume-5-number-2/multi-generation-family-in-estonia-multipleroles-and-the-stress-of-living-together-with-elderly-people.html\#sthash.kfmlP8Di.dpbs.

Laidmäe, V.-I., Tulva, T. and Sepp, M. 2009. Attitudes of the middle-aged towards ageing in Estonia. The Internet Journal of Geriatrics and Gerontology, 5, 1. Available online at http://archive.ispub.com/journal/the-internet-journal-of-geriatrics-andgerontology/volume- 5 -number- 1 / attitudes-of-the-middle-aged-towards-ageingin-estonia.html\#sthash.xMNNpbgh.dpbs.

Lauristin, M. 1997. Context of transition. In Lauristin, M., Vihalemm, P., Rosengren, K. E. and Weibull, L. (eds), Return to the Western World. Cultural and Political Perspectives on the Estonian Post-Communist Transition. Tartu University Press, Tartu, Estonia, $25^{-4}$.

Lehr, U. 1984. The role of women in the family generation context. In GarmsHomolova, V., Hoerning, E. M. and Schaeffer, D. (eds), Intergenerational Relationships. Hogrefe, Goltingen, Germany, $125^{-32 .}$

Lei, L. 2013. Sons, daughters, and intergenerational support in China. Chinese Sociological Review, 45, 3, 26-52.

Lin, C. C. and Fu, V. 1990. A comparison of child-rearing practices among Chinese, immigrant Chinese, and Caucasian-American parents. Child Development, 61, 2, 429-33.

Litwin, H. and Shiovitz-Ezra, S. 2006. The association between activity and well-being in later life: what really matters? Ageing $\mathcal{E}$ Society, 26, 2, 225 -42.

Liu, L.J. and Guo, Q. 2007. Loneliness and health-related quality of life for the empty nest elderly in the rural area of a mountainous county in China. Quality of Life and Research, 16, 8, $1275^{-80}$.

Lowenstein, A. 2007. Solidarity-conflict and ambivalence: testing two conceptual frameworks and their impact on quality of life for older family members. Journal of Gerontology: Social Sciences, 62, 2, S100-7.

Lowenstein, A., Katz, R. and Gur-Yaish, N. 2007. Reciprocity in parent-child exchange and life satisfaction among the elderly: a cross-national perspective. Journal of Social Issues, $\mathbf{6}_{3}, 4,865^{-83}$.

Martin, M. and Westerhof, G.J. 2003. Do you have to have them or should you believe you have them? Resources, their appraisal, and well-being in adulthood. Journal of Adult Development, 1o, 2, 99-112.

Mayer, B. 2013. Family Change Theory: a preliminary evaluation on the basis of recent cross-cultural studies. In Albert, I. and Ferring, D. (eds), Intergenerational Relations. European Perspectives on Family and Society. Policy Press, Bristol, UK, $167-87$.

Mayer, B., Albert, I., Trommsdorff, G. and Schwarz, B. 2005. Value of children in Germany: dimensions, comparisons of generations, and relevance for parenting. 
In Trommsdorff, G. and Nauck, B. (eds), The Value of Children in Cross-cultural Perspective: Case Studies from Eight Societies. Pabst Science, Lengerich, Germany, 43-66.

Mitterauer, M. and Kagan, A. 1982. Russian and central European family structures: a comparative view. Journal of Family History, 7, 1, 103-31.

Moor, N. and Komter, A. 2008. Demographic Changes, Intergenerational Solidarity and Well-being in Europe: A Comparative Approach. Available online at http://www. multilinks-project.eu/uploads/papers/oooo/o035/Demographic_changes_inter generational_solidarity_and_well-being_in_Europe_finalMoor_Komter_.pdf [Accessed April 2008].

Narusk, A. and Hansson, L. 1999. Estonian Families in the I99os: Winners and Losers. Estonian Academy Publishers, Tallinn.

Nauck, B. 2009. Patterns of exchange in kinship systems in Germany, Russia, and the People's Republic of China. Journal of Comparative Family Studies, 4o, 2, $255^{-78}$.

Ng, S. H. 2002. Will families support their elders? Answers from across cultures. In Nelson, T. D. (ed.), Ageism: Stereotyping and Prejudice Against Older Persons. MIT Press, Cambridge, Massachusetts, 295-309.

Pajumets, M. 201 2. Post-socialist masculinities, identity work, and social change: an analysis of discursive (re)constructions of gender identity in novel social situations. $\mathrm{PhD}$ dissertation, Tallinn University, Tallinn.

Rice, T. W. and Steele, B. J. 2004. Subjective well-being and culture across time and space. Journal of Cross-cultural Psychology, 35, 6, 633-47.

Rossi, A. S. 1993. Intergenerational relations: gender, norms, and behavior. In Bengtson, V.L. and Achenbaum, W.A. (eds), The Changing Contract Across Generations. Aldine de Gruyer, New York, 191-212.

Rossi, A. S. and Rossi, P. H. 199o. Of Human Bonding: Parent-Child Relations Across the Life Course. Aldine de Gruyter, New York.

Rothbaum, F., Weisz, J., Pott, M., Miyake, K. and Morelli, G. 200o. Attachment and culture: security in the United States and Japan. American Psychologist, 55, 10, 1093-104.

Saris, W. E. 2001. What influences subjective well-being in Russia? Journal of Happiness Studies, 2, 2, 137-46.

Schwarz, B. 2006. Adult daughters' family structure and the association between reciprocity and relationship quality. Journal of Family Issues, 27, 2, 208-28.

Schwarz, B., Albert, I., Trommsdorff, G., Zheng, G., Shi, S. and Nelwan, P. R. 2010 a. Intergenerational support and life satisfaction: a comparison of Chinese, Indonesian, and German elderly mothers. Journal of Cross-cultural Psychology, 41, 5/6, 706-22.

Schwarz, B., Trommsdorff, G., Albert, I. and Mayer, B. 2005. Adult parent-child relationship: relationship quality, support, and reciprocity. Applied Psychology: An International Review, 54, 3, 396-417.

Schwarz, B., Trommsdorff, G., Zheng, G. and Shi, S. 2010 b. Reciprocity in intergenerational support: a comparison of Chinese and German adult daughters. Journal of Family Issues, 31, 2, 234-56.

Schyns, P. 1998. Cross-national differences in happiness: economic and cultural factors explored. Social Indicators Research, 43, 1/2, 3-26.

Shi, L.Y. 1993. Family financial and household support exchange between generations: a survey of Chinese rural elderly. The Gerontologist, 33, 4, $4^{68-80 .}$

Silverstein, M. and Bengtson, V. L. 1991. Do close parent-child relations reduce the mortality risk of older parents? Journal of Health and Social Behavior, 32, 4, $3^{82-95}$. 
Suh, E., Diener, E., Oishi, S. and Triandis, H. C. 1998. The shifting basis of life satisfaction judgments across cultures: emotions versus norms. Journal of Personality and Social Psychology, 74, 2, 482-93.

Sun, R. J. 2002. Old age support in contemporary urban China from both parents' and children's perspectives. Research on Aging, 24, 3, 337-59.

Sung, K.-T. 1995. Measures and dimensions of filial piety in Korea. The Gerontologist, 35, 2, 240-7.

Szydlik, M. 2008. Intergenerational solidarity and conflict. Journal of Comparative Family Studies, 39, 1, 97-1 14.

Triandis, H. C. 1989. The self and social behavior in differing cultural contexts. Psychological Review, 96, 3, 506-20.

Troll, L.E. 1987. Mother-daughter relationships through the lifespan. In Oskamp, S. (ed.), Family Processes and Problems: Social Psychological Aspects. Sage, Newbury Park, California, 284-3o6.

Troll, L. E. and Smith, J. 1976. Attachment through the lifespan: some questions about dyadic bonds among adults. Human Development, 19, 3, $155^{6-70 .}$

Trommsdorff, G. and Kornadt, H.-J. 2003. Parent-child relations in cross-cultural perspective. In Kuczynski, L. (ed.), Handbook of Dynamics in Parent-Child Relations. Sage, Thousand Oaks, California, 271-306.

Trommsdorff, G. and Mayer, B. 2012. A cross-cultural study of intergenerational relations: the role of socioeconomic factors, values, and relationship quality in intergenerational support. In Bertram, H. and Ehlert, N. (eds), Family, Ties, and Care: Family Transformation in a Plural Modernity. Barbara Budrich Publishers, Berlin, 315-42.

Trommsdorff, G. and Nauck, B. (eds) 2005. The Value of Children in Cross-cultural Perspective. Case Studies from Eight Societies. Pabst Science, Lengerich, Germany.

Trommsdorff, G., Nauck, B., Schwarz, B., Chakkarath, P. and Schwenk, O. 2002. The Value of Children Questionnaire. Unpublished questionnaire, University of Konstanz, Germany.

Trommsdorff, G. and Schwarz, B. 2007. The 'intergenerational stake hypothesis' in Indonesia and Germany: adult daughters' and their mothers' perception of their relationship. Current Sociology, 55, 4, 599-620.

Uchida, Y. and Ogihara, Y. 201 2. Personal or interpersonal construal of happiness: a cultural psychological perspective. International Journal of Wellbeing, 2, 4, 354-69.

Veenhoven, R. 1997. Quality-of-life in individualistic society, a comparison of 43 nations in the early 1990s. In Vanderbraak, H., DeJong, M.J. and Zijderveld, A. C. (eds), The Gift of Society: Social Capital and Institutions in a (Post) Modern World. Enzo Press, Amersfoort, The Netherlands, 157-86.

Wang, J. K. and Zhao, X. D. 2011. Empty nest syndrome in China. International Journal of Social Psychiatry, 58, 1, 110.

$\mathrm{Xu}, \mathrm{Q}$. and Yuan, Y. 1997. The role of family support in the old-age security in China. In China Population Association (ed.), The 23 rd IUSSP General Population Conference: Symposium on Demography of China. Xin Hua Press, Beijing, $265^{-73}$.

Yang, H. 1996. The distributive norm of monetary support to older parents: a look at a township in China. Journal of Marriage and Family, 58, 2, 404-15.

Yuan, F. 1987 . The status and role of the Chinese elderly in families and society. In Schulz, J. H. and Davis-Friedmann, D. (eds), Aging China: Family, Economics, and Government Policies in Transition. The Gerontological Society of America, Washington DC, $3^{6-46 .}$

Yue, X. D. and Ng, S. H. 1999. Filial obligations and expectations in China: current views from young and old people in Beijing. Asian Journal of Social Psychology, 2, 2, $215^{-26 .}$ 
1294 Jing Wu et al.

Zheng, G., Shi, S. H. and Tang, H. 2005. Population development and the value of children in the People's Republic of China. In Trommsdorff, G. and Nauck, B. (eds), The Value of Children in Cross-cultural Perspective: Case Studies from Eight Societies. Pabst Science, Lengerich, Germany 239-82.

Accepted 9 April 2015; first published online I I May 2015

Address for correspondence:

Jing Wu, Estonian-Swedish Mental Health and

Suicidology Institute, Õie 39, Tallinn, 11615 , Estonia

E-mail: wujingsweet@gmail.com 